\title{
Efektivitas Alat Sikat Gigi Otomatis Wall Mounted untuk Disabilitas pada SLB di Jember terhadap Indeks Kebersihan Mulut
}

\section{(Effectiveness Wall Mounted Automatical Tootbrush for Disability in SLB Jember on Oral Hygiene Index)}

\author{
Arina Rosyida ${ }^{1}$, Kiswaluyo ${ }^{2}$, Surartono Dwiatmoko ${ }^{3}$ \\ ${ }^{1}$ Program Studi Pendidikan Dokter Gigi Fakultas Kedokteran Gigi Universitas Jember \\ 2Dosen, Bagian IKGM, Fakultas Kedokteran Gigi, Universitas Jember \\ ${ }^{3}$ Dosen, Bagian IKGM, Fakultas Kedokteran Gigi, Universitas Jember \\ JIn. Kalimantan No.37, Kampus Tegalboto, Jember 68121 \\ E-mail korespondensi: arinnaluyan@gmail.com
}

\begin{abstract}
Disability is a person with disabilities who has physical, mental, intellectual, sensory, and some motor disorders. Disabilities that have motor impairments are blind, mentally retarded, and disabled so they need an automatic wall mounted toothbrush in cleaning teeth and mouth. Wall mounted toothbrush is an innovative tool for blind, mentally disabled and disabled people to be able to brush their teeth independently. The aims is to determine the effectiveness of automatic wall mounted toothbrushes in children with disabilities, especially in the visually impaired, mentally retarded, and disabled. The study was conducted by pre-experimental method (One Group Pretest-Posttest Design) in SLB disabled people in Jember with 56 people, 17 people with visual impairment, 36 mental retardation, and 3 disabled people. The results of the study carried out a paired sample t test showed a significance value $(p<0.05)$ in the blind and mentally retarded while the significance value $(p>0.05)$ in the disabled. The conclusion of the study is that this tool is effective in the blind and mentally retarded but is less effective in the disabled.
\end{abstract}

Keywords: Disability, visually impaired, mentally retarded, disabled, automatic wall mounted toothbrush

\begin{abstract}
Abstrak
Disabilitas merupakan penyandang kecacatan yang memiliki gangguan pada fisik, mental, intelektual, sensorik, dan beberapa motorik. Disabilitas yang memiliki gangguan motorik adalah tunanetra, tunagrahita, dan tunadaksa. Gangguan motorik dapat menghambat proses menyikat gigi pada anak disabilitas sehingga kebersihan mulut mereka buruk. Saat ini telah banyak beredar jenis sikat gigi namun belum maksimal penggunaanya pada anak disabilitas sehingga diperlukan suatu alat yang dapat membantu kerja anak disabilitas dalam menjaga kebersihan mulut. Alat sikat gigi otomatis wall mountedsebagai inovasi alat bantu disabilitas diharapkan mampu memudahkan dalam membersihkan gigi dan mulut.Penelitian bertujuan mengetahui efektivitas alat sikat gigi otomatis wall mounted pada anak penyandang disabilitas terutama pada tunanetra, tunagrahita, dan tunadaksa. Penelitian dilakukan dengan carapra-eksperimental (One Group Pretest-Posttest Design) padapenyandang disabilitas SLB di Jember sebanyak 56 orang yaitu17 tunanetra, 36 tunagrahita, dan 3 tunadaksa. Hasil penelitian dilakukan uji paired sample t test menunjukkan nilai signifikansi $(p<0,05)$ pada tunanetra dan tunagrahita sedangkan nilai signifikansi $(p>0,05)$ pada tunadaksa. Kesimpulan penelitian adalah alat ini efektif pada tunanetra dan tunagrahita tetapi kurang efektif pada tunadaksa.
\end{abstract}

Kata kunci : Disabilitas, Tunanetra, Tunagrahita, Tunadaksa, Alat sikat gigi otomatis wall mounted 


\section{Pendahuluan}

Disabilitas merupakan penyandang kecacatan fisik, mental, intelektual, atau sensorik dalam jangka waktu lama di mana interaksi dengan berbagai hambatan dapat menyulitkan partisipasi penuh dan efektif dalam masyarakat [1].Tunadaksa adalah seseorang yang mengalamikecacatan dalam fisik [2] dan kelainan yang mereka miliki sifatnya menetap pada alat gerak, yaitu tulang, sendi, otot [3]. Tunanetra merupakan seseorang yang mengalami gangguan daya penglihatan berupa kebutaan menyeluruh (total) atau sebagian (low vision). Penyebab tunanetra dipengaruhi oleh beberapa faktor, diantaranya adalah prenatal dan postnatal [4]. Tunagrahita merupakan individu yang mengalami hambatan atau keterlambatan perkembangan mental jauh di bawah rata-rata sehingga mengalami kesulitan untuk belajar, berkomunikasi, dan bersosialisasi.

Penyandang ketiga ketunaan tersebut memiliki kelemahan dalam kemampuan berpikir dan bernalar,kondisi ini menyebabkan penyandang ketunaan kurang mampu dalam merawat diri secara mandiriseperti menggosok gigi[5]. Ketelitian dalam menggosok gigi diperlukan kemampuan atau keterampilan tangan individu yang baik saat menyikat gigi[6].Pusat Data Informasi Nasional (PUSDATIN) Kementrian Sosial tahun 2010, tercatat jumlah penyandang disabilitas di Indonesia berjumah 11.580 .117 orang dengan perincian tunanetra berjumlah 3.474.035, tunadaksa berjumlah 3.010 .830 orang, 2.547.626 tunarungu, 1.389.614 tunagrahita, dan 1.158.012 penyandang disabilitas kronis. Jumlah ini di prediksi akan terus meningkat diikuti dengan semakin meningkatnya angka kecelakaan dan berdasarkan data Kementerian Sosial Republik Indonesia tahun 2011 menyatakan bahwa jumlah individu dengan keterbatasan fisik yaitu 2.126.785[5].

Disabilitas (tunadaksa, tunanetra, dan tunagrahita) memiliki kekurangan kemampuan motorik yang dapat menyulitkan dalam menyikat gigi. Adanya keterbatasan yang dimiliki anak disabilitas, peneliti mencoba merancang dan menggunakan alat sikat gigi otomatis wall mounted yang diharapkan dapat mempermudah disabitas dalam menyikat gigi tanpa bantuan orang lain. Sikat gigi otomatis wall mounted, ini nantinya akan dicobakan pada disabilitas yang berada pada SLB di Jember.

\section{Metode Penelitian}

Penelitian menggunakan jenis penelitian yaitu pra-eksperimendan rancangan penelitian menggunakan one group pretest-posttest design yaitu rancangan yang dilakukan pada satu kelompok saja tanpa kelompok pembanding sehingga besarnya efek dari eksperimen dapat diketahui dengan pasti. Metode pengambilan data secara cross sectional yaitu pendekatan yang mencakup semua jenis penelitian yang pengukuran variabel-variabelnya dilakukan hanya satu kali dalam satu periode.Sampel penelitiansebanyak 56 siswa penderita tunadaksa, tunanetra, dan tunagrahita pada SLB di Jember.Sampel di ambil secara total sampling yaitu suatu pengambilan sampel yang dilakukan dengan cara memakai seluruh populasi dalam pelaksanaan penelitian. Total sampling ini dilakukan jika jumlah populasi relatif kecil.Sampel yang digunakan adalah tunanetra, tunagrahita, dan tunadaksa pada beberapa SLB di Jember yaitu di SLB TPA Bintoro,SLBN Patrang dan SLB YPAC.

Tahap pertama yaitu melakukan pengukuran kebersihan gigi dan mulut menggunakan OHI-S Greene dan Vermillion kemudian menguji coba alat sikat gigi otomatis wall mounted.Tahap berikutnya adalah melakukan pemeriksaan OHI-S Greene dan Vermillion setelah menggunaka sikat gigi otomatis wall mounted. Kriteria penilaian OHI-S Greene dan Vermillion berdasarkan keadaan endapan lunak atau debris dan karang gigi atau kalkulus. Pemeriksaan pada 6 gigi yaitu gigi 16, $11,26,36,31$, dan 46. Pada gigi 16, 11, 26, 31 yang dilihat permukaan bukalnya sedangkan gigi 36 dan 46 permukaan lingualnya. Indeks debris yang dipakai adalah Debris Indeks (D.I) Greene dan Vermillion (1964) dengan kriteria :[7]

$0=$ tidak ada debris lunak

1 = terdapat selapis debris lunak menutupi tidak lebih dari $1 / 3$ permukaan gigi

2 = terdapat selapis debris lunak menutupi lebih dari $1 / 3$ permukaan gigi tetapi tidak lebih dari 2/3 permukaan gigi

$3=$ terdapat selapis debris lunak menutupi lebih dari 2/3 permukaan gigi

Sedangkan indeks kalkulus yang digunakan adalah Calculus Indeks (C.I) Greene dan Vermillion (1964) yaitu:

$0=$ tidak ada kalkulus

1 = kalkulus supragingiva menutupi tidak lebih dari $1 / 3$ permukaan gigi

$2=$ kalkulus supragingiva menutupi lebih dari $1 / 3$ permukaan gigi tetapi tidak lebih dari $2 / 3$ permukaan gigi atau kalkulus subgingival berupa bercak hitam di sekitar leher gigi atau terdapat keduanya

3 = kalkulus supragingiva menutupi lebih dari $2 / 3$ permukaan gigi atau kalkulus subgingiva berupa cincin hitam di sekitar leher gigi atau terdapat keduanya.

Pemeriksaan debris dan kalkulus dilakukan dengan menggunakan kacamulut, senter, dan sonde kemudian disesuaikan skor dengan 
kriteria D.I dan C.I Greene dan Vermillion (1964). OHI-S didapatkan dari pemasukkan rumus yaitu D.I + C.I Kriteria skor OHI-S adalah sebagai berikut: [7]

Tabel 1. Kriteria penilaian OHI-S

\begin{tabular}{cc}
\hline Kriteria Penilaian & Nilai OHI-S \\
\hline Baik (good) & $0-1,2$ \\
\hline Sedang (fair) & $1,3-3,0$ \\
\hline Buruk (poor) & $3,1-6,0$ \\
\hline
\end{tabular}

\section{Hasil Penelitian}

Penelitian dilakukan pada siswa-siswi yang mengalami disabilitas yaitu tunagrahita, tunanetra, dan tunadaksa.Peneliti mengambil sampel di SLB yang berada di Jember, yaitu SLB YPAC, SLBN Patrang, dan SLB TPA Bintoro.Penelitian ini dilaksanakan pada bulan Oktober 2018 sampai April 2019. Penelitian tersebut bertujuan untuk mengetahui skor $\mathrm{OHI}-\mathrm{S}$ siswa-siswi disabilitas di lihat dari indeks $\mathrm{OHI}-\mathrm{S}$ Greene dan Vermillion antara perlakuan sebelum menyikat gigi dan sesudah menyikat gigi dengan menggunakan alat sikat gigi otomatis wall mounted.Data hasil penelitian yang diperoleh dilakukan analisa secara statistik dengan menggunakan SPSS versi 25.

Hasil uji normalitas pada data hasil penelitian ini adalah nilai $p=0,2$ yang berarti data tersebut terdistribusi normal karena $p>0,05$. Kemudian dilakukan uji Paired sample t test pada masing-masing disabilitas (tunanetra, tunagrahita, dan tunadaksa) untuk mengetahui perbedaan hasil ohi-s sebelum dan sesudah penggunaan alat sikat gigi otomatis wall mounted.

Tabel 2. Hasil uji paired sample t test

\begin{tabular}{llll}
\hline & $\begin{array}{l}\text { Post } \\
\text { tunanetra }\end{array}$ & $\begin{array}{l}\text { Post } \\
\text { tunagra } \\
\text { hita }\end{array}$ & $\begin{array}{l}\text { Post } \\
\text { tunadak } \\
\text { sa }\end{array}$ \\
\hline $\begin{array}{l}\text { Pre } \\
\text { tunanetra }\end{array}$ & 0,000 & - & - \\
\hline $\begin{array}{l}\text { Pre } \\
\text { tunagrahita }\end{array}$ & - & 0,000 & - \\
\hline $\begin{array}{l}\text { Pre } \\
\text { tunadaksa }\end{array}$ & - & - & 0,172 \\
\hline
\end{tabular}

Berdasarkan uji paired sample $t$ test pada masing-masing disabilitas terdapat perbedaan yang signifikan $p=0,000(p<0,05)$ pada penyandang tunanetra dan tunagrahita sedangkan tidak terdapat perbedaan yang signifikan pada penyandang tunadaksa $p=0,172$ $(p>0,05)$.

\section{Pembahasan}

Penelitian ini menggunakan anak disabilitas di SLB Jember untuk uji coba alat sikat gigi otomatis wall mounted. Pemilihan anak disabilitas untuk penelitian ini dikarenakan anak disabilitas mengalami sedikit gangguan pada motoriknya. Penelitian ini bertujuan untuk mengetahui efektivitas alat sikat gigi otomatis wall mounted sehingga dilakukan pemeriksaan indeks OHI-S pada anak disabilitas ini sebelum dan sesudah penggunaan alat sikat gigi otomatis wall mounted. Pemeriksaan OHI-S dilakukan dengan menghitung $\mathrm{DI}$ dan $\mathrm{Cl}$ pada 6 gigi anak disabilitas ( gigi 11, 31, 26, 16, 36, dan 46 ) dan dimasukkan rumus perhitungan $\mathrm{OHI}-\mathrm{S}$ Greene dan Vermillion (1964). Pada pemeriksaan DI digunakan pemberian disclosing solution lalu dilihat dengan kacamulut kemudian dicocokkan dengan tabel kategori DI Greene dan Vermillion (1964) sedangkan untuk pemeriksaan $\mathrm{Cl}$ digunakan sonde lurus dan kacamulut selanjutnya dicocokkan dengan tabel kategori Greene dan Vermillion (1964).

Pada penelitian ini, alat sikat gigi otomatis wall mounted tidak begitu bekerja pada penyandang tunadaksa terutama tunadaksa kategori tunadaksa cerebral palsy. Tunadaksa cerebral palsy merupakan suatu kelainan gerak, bentuk tubuh, gangguan koordinasi, gangguan psikologis, dan sensoris yang disebabkan oleh adanya kerusakan pada masa perkembangan otak[2]. Karakteristik tunadaksa cerebral palsy secara emosional tinggi, mudah marah, mudah tersinggung, pemalu, dan rata-rata pada tunadaksa cerebral palsy ini memiliki tingkat kecerdasan yang rendah [2].

Hasil data penelitian dari ke 56 siswa-siswi disabilitas dilakukan uji normalitas Kolmogorov Smirnov karena sampel lebih dari 50. Hasilnya adalah data tersebut normal karena $p=0,2(p>$ $0,05)$, selanjutnya dilakukan analisis Paired sample $t$ test untuk mengetahui perbandingan peningkatan kebersihan gigi dan mulut pre-post pemakaian alat pada masing-masing disabilitas yaitu tunanetra, tunagrahita dan tunadaksa. Data indeks $\mathrm{OHI}$-S masing-masing disabilitas di olah pada uji Paired sample t test dan diperoleh data terdapat beda yang signifikan pada indeks $\mathrm{OHI}$ $S$ pre-post pemakaian alat untuk tunanetra dan tunagrahita sedangkan tidak terdapat beda pada hasil indeks $\mathrm{OHI}$-S pre-post pemakaian alat untuk tunadaksa. Hal ini terjadi karena tunadaksa memiliki gangguan gerak yang disebabkan oleh kelainan neuromuskular termasuk celebral palsy [3]. Tunadaksa yang berada di SLB Jember termasuk tunadaksa berkategori sedang dan berat. Tunadaksa sedang memiliki keterbatasan motorik dan mengalami gangguan koordinasi sensorik sedangkan tunadaksa berat memiliki 
keterbatasan total dalam gerakan fisik dan tidak mampu mengontrol gerakan fisik[3].

Kelemahan alat sikat gigi otomatis wall mounted yaitu alat ini masih kurang efektif untuk penyandang disabilitas kategori sedang dan berat. Pada hasil penelitian bisa dilihat bahwa penyandang tunadaksa tidak begitu terlihat perbedaan yang signifikan terlebih lagi pada penyandang tunadaksa cerebral palsy.Alat ini juga masih sedikit rapuh, jika digunakan lebih dari 20 kali pemakaian dalam sehari. Kelemahan lainnya dari alat ini diperlukan untuk memotong sikat gigi yang akan dipakai dikarenakan alat ini berukuran tidak terlalu besar sehingga panjang sikat gigi tidak bisa dipasangkan pada alat, jika tidak dilakukan pemotongan.

\section{Simpulan dan Saran}

Berdasarkan hasil penelitian, maka dapat disimpulkan bahwa alat sikat gigi otomatis wall mounted efektif pada anak penyandang tunanetra dan anak penyandang tunagrahita dalam membersihkan gigi dan mulut mereka tetapi alat ini kurang efektif membersihkan gigi dan mulut pada anak penyandang tunadaksa.Perlu adanya penelitian lebih lanjut pada alat sikat gigi otomatis wall mounted agar dapat lebih efektif dalam meningkatkan indeks OHI-S pada penyandang tunadaksa sedang dan berat.Perlu dilakukan perakitan alat sikat gigi otomatis wall mounted agar biaya pembuatan alat tidak terlalu mahal dan dapat didistribusikan ke masyarakat luas.Alat ini masih tidak ergonomis.Alat ini akan lebih baik jika dapat di charger, tanpa menggunakan energi listrik secara langsung.

\section{Daftar Pustaka}

[1] Hamidi J. 2016. Perlindungan Hukum terhadap Disabilitas dalam Memenuhi Hak Mendapatkan Pendidikan dan Pekerjaan. Jurnal Hukum Ius Quia Iustum. 23(4) : 653657.

[2] Pratiwi I, dan Hartosujono. 2014. Resiliensi pada Penyandang Tuna Daksa Non Bawaan. Jurnal SPIRITS. 5(1) : 48-54.

[3] Kencana IGS. 2014. Peranan Perawat Gigi dalam Pemeliharaan Kesehatan Gigi dan Mulut pada Anak Berkebutuhan Khusus (Disabled Children). Jurnal Kesehatan Gigi. 2(2) : 260-265.

[4] Sabilillah MF, Kristiani A. 2017. Hubungan Oral Hygiene dengan Keterampilan Menggosok Gigi pada Anak Tunanetra. EJournal. 2(2) : 23-28.

[5] Merdiasi D. 2013. Gambaran Tuna Daksa yang Bekerja. Jurnal NOETIC Psychology. 3(2) : 163-184.

[6] Pratiwi L, dan Sandy A. 2017. Peran Orang Tuan terhadap Keterampilan Menyikat Gigi dan Mulut pada Anak Disabilitas Intelektual. Jurnal Teknosains. 7(1) : 53-58.

[7] Basuni C, dan Putri DKT. 2014. Gambaran Indeks Kebersihan Mulut Berdasarkan Tingkat Pendidikan Masyarakat di Desa Guntung Ujung Kabupaten Banjar. Dentino Jurnal Kedokteran Gigi. 2(1) : 18-23. 